\title{
Impact of brief prewarming on anesthesia- related core-temperature drop, hemodynamics, microperfusion and postoperative ventilation in cytoreductive surgery of ovarian cancer: a randomized trial
}

L. Kaufner ${ }^{1 *}$ (D) P. Niggemann ${ }^{1}$, T. Baum ${ }^{1}$, S. Casu ${ }^{2}$, J. Sehouli ${ }^{3}$, A. Bietenbeck ${ }^{4}$, M. Boschmann ${ }^{5}$, C. D. Spies ${ }^{1}$, A. Henkelmann ${ }^{1}$ and C. von Heymann ${ }^{2}$

\begin{abstract}
Background: General (GA)- and epidural-anesthesia may cause a drop in body-core-temperature (BCT drop), and hypothermia, which may alter tissue oxygenation $\left(\mathrm{StO}_{2}\right)$ and microperfusion after cytoreductive surgery for ovarian cancer. Cell metabolism of subcutaneous fat- or skeletal muscle cells, measured in microdialysis, may be affected. We hypothesized that forced-air prewarming during epidural catheter placement and induction of GA maintains normothermia and improves microperfusion.

Methods: After ethics approval 47 women scheduled for cytoreductive surgery were prospectively enrolled. Women in the study group were treated with a prewarming of $43^{\circ} \mathrm{C}$ during epidural catheter placement. BCT (Spot on ${ }^{\oplus}, 3 \mathrm{M}$ ) was measured before $\left(T_{1}\right)$, after induction of $G A\left(T_{2}\right)$ at 15 min $\left(T_{3}\right)$ after start of surgery, and until $2 \mathrm{~h}$ after ICU admission ( $\left.T_{1 C U 2 h}\right)$. Primary endpoint was $B C T_{\text {drop }}$ between $T_{1}$ and $T_{2}$. Microperfusion-, hemodynamic- and clinical outcomes were defined as secondary outcomes. Statistical analysis used the Mann-Whitney-U- and non-parametric-longitudinal tests.

Results: $\mathrm{BC}$ drop was $0.35^{\circ} \mathrm{C}$ with prewarming and $0.9^{\circ} \mathrm{C}$ without prewarming $(p<0.005)$ and $\mathrm{BCT}$ remained higher over the observation period $\left(\Delta \mathrm{T}_{4}=0.9^{\circ} \mathrm{C}\right.$ up to $\left.\Delta \mathrm{T}_{7}=0.95^{\circ} \mathrm{C}, p<0.001\right)$. No significant differences in hemodynamic parameters, transfusion, arterial lactate and $\mathrm{dCO}_{2}$ were measured. In microdialysis the ethanol ratio was temporarily, but not significantly, reduced after prewarming. Lactate, glucose and glycerol after PW tended to be more constant over the entire period. Postoperatively, six women without prewarming, but none after prewarming were mechanical ventilated $(p<0.001)$.
\end{abstract}

Conclusion: Prewarming at $43^{\circ} \mathrm{C}$ reduces the $B C T_{\text {drop }}$ and maintains normothermia without impeding the perioperative routine patient flow. Microdialysis indicate better preserved parameters of microperfusion.

Trial registration: ClinicalTrials.gov; ID: NCT02364219; Date of registration: 18-febr-2015.

Keywords: Prewarming, Ovarian cancer, Microperfusion, Normothermia

\footnotetext{
* Correspondence: lutz.kaufner@charite.de

'Department of Anaesthesiology and Operative Intensive Care Medicine (CCM, CVK), Charité-Universitätsmedizin Berlin, Corporate Member of Freie Universität Berlin, Humboldt-Universität zu Berlin, and Berlin Institute of Health, Campus Virchow-Klinikum, Augustenburger Platz 1, 13353 Berlin, Germany

Full list of author information is available at the end of the article
}

(c) The Author(s). 2019 Open Access This article is distributed under the terms of the Creative Commons Attribution 4.0 International License (http://creativecommons.org/licenses/by/4.0/), which permits unrestricted use, distribution, and reproduction in any medium, provided you give appropriate credit to the original author(s) and the source, provide a link to the Creative Commons license, and indicate if changes were made. The Creative Commons Public Domain Dedication waiver (http://creativecommons.org/publicdomain/zero/1.0/) applies to the data made available in this article, unless otherwise stated. 


\section{Background}

The incidence of inadvertent perioperative hypothermia in surgery, defined as a body core temperature (BCT) below $36{ }^{\circ} \mathrm{C}$, is still high $[1,2]$. A shift of thresholds for vasoconstriction and shivering as well as sympathicolysisrelated vasodilatation caused by epidural anesthesia (EDA) result in a redistribution of warm blood from the body core to the periphery [3]. Furthermore, the induction of general anesthesia (GA) aggravates redistribution hypothermia up to $1.5^{\circ} \mathrm{C}$ [4]. Cytoreductive surgery for ovarian cancer is characterized by maximum extent of tumour debulking including deperitonea-lisation and massive volume shifts and losses [5]. Stabilisation of the BCT, therefore, requires forced air warming and administration of warmed infusions and transfusions. However, maintainance of normothermia is jeopardized by an anesthesia-reduced base metabolic rate and heat production [5]. Perioperative hypothermia may affect coagulation by altered platelet function $[6,7]$ and increase intraoperative blood loss [8]. Furthermore, hypothermia-related vasoconstriction may impair microperfusion and reduce the oxygen partial pressure and oxygen saturation $\left(\mathrm{StO}_{2}\right)$ in peripheral tissues [9]. As a result of impaired microperfusion cell metabolism of subcutaneous fat- or skeletal muscle cells, measured in microdialysis (MD), may be affected [10].

Preoperative forced-air warming (prewarming) of 10 to $60 \mathrm{~min}$ at $43^{\circ} \mathrm{C}$ [11-15] before induction of $\mathrm{GA}$ has been shown to reduce the temperature gradient between body core and periphery [16] in order to alleviate redistribution hypothermia $[3,16]$ and to maintain intraoperative normothermia [17] in minor surgery (without EDA) [11] or major abdominal surgery with EDA [12]. However, these studies required holding areas to realize prewarming and a timely patient flow. From a surgical point of view, in major cytoreductive surgery with a duration of more than $180 \mathrm{~min}$ it still remains unclear whether a brief prewarming during insertion of EDA is effective to maintain intra- and postoperative normothermia and to improve intraoperative hemodynamics and microperfusion as well as to reduce postoperative shivering and ventilation [18].

We hypothesized that a forced-air prewarming interval of $30 \mathrm{~min}$ at $43{ }^{\circ} \mathrm{C}$ during epidural catheter placement and induction of GA without any changes of the perioperative patient flow (e.g. no treatment in a preoperative holding area) is effective to maintain perioperative normothermia and improve microperfusion during cytoreductive surgery for ovarian cancer.

\section{Methods}

This single-center prospective randomized clinical trial was conducted at the Departments of Anesthesiology and Intensive Care Medicine and Gynecology of the CharitéUniversitätsmedizin Berlin, Germany. Ethics approval was obtained from the institutional ethics committee (EA1/ 348/14, ClinicalTrials.govID: NCT02364219). Women were enrolled if they were of age ( $>18$ years), mentally healthy, American Society of Anesthesiologists physical status Class I-III and scheduled to undergo elective major cytoreductive surgery in primary or secondary ovarian cancer under combined epidural and general anesthesia. Exclusion criteria were: heart failure (left ventricular ejection fraction (LV-EF) <30\%), chronic obstructive pulmonary disease (GINA-Classification $>3$ ), renal failure (glomerular filtration rate $($ GFR $)<50 \mathrm{ml} / \mathrm{min}$ ) or dialysis, participation in another clinical trial and contraindication of EDA including non-eligibility due to refusal of neuraxial anesthesia.

After written informed consent and before surgery, women were prospectively randomized into prewarming (prewarm) and standard group (standard) using a computer-generated block randomization (Excel, Microsoft Corporation, Redmont, WA, USA). Additionally, a subgroup of the standard- and the prewarm group were randomly assigned for microdialysis (MD) measurements. The randomization was concealed. Randomization was blinded, the anesthesist during surgery was not randomized and the data evaluation took place independently from the surgery anesthesist.

According to randomization, women in the prewarming group received forced-air warming at $43{ }^{\circ} \mathrm{C}$, during the establishment of epidural anesthesia. Prewarming was applied using a forced air warming gown (Bair Paws ${ }^{\mathrm{TM}}$ Flex Warming Gown, $3 \mathrm{M}^{\mathrm{m}}$, St. Paul, MN, USA) connected to a forced air warmer (Bair Hugger ${ }^{\mathrm{T}}$, Model 750, $3 \mathrm{M}^{\mathrm{TM}}$, St. Paul, MN, USA), which warms the front of the body including upper arms (Fig. 1a). In the standard treatment group, patients were covered by a cotton blanket for passive insulation without active warming during the insertion of the epidural catheter.

The perioperative anesthetic setting in both groups was based on the clinical practice and standard operating procedures of the Department. Upon arrival in the operating room (OR), a peripheral vein cannula was inserted and an infusion of balanced crystalloid solution was started under standard monitoring. Body core temperature was taken by using the SpotOn ${ }^{\mathrm{TM}}$ temperature system $\left(3 \mathrm{M}^{\mathrm{TM}}\right.$; St. Paul, MN, USA) in both groups and throughout the observation period [19]. Perioperative body core temperatures were manually recorded in the case reporting form (CRF) at admission to the OR $\left(\mathrm{T}_{1}\right)$, insertion of epidural catheter and induction of GA $\left(\mathrm{T}_{2}\right)$ as well as after $15 \mathrm{~min}\left(\mathrm{~T}_{3}\right)$, $60 \min \left(\mathrm{T}_{4}\right), 120 \mathrm{~min}\left(\mathrm{~T}_{5}\right), 180 \mathrm{~min}\left(\mathrm{~T}_{6}\right)$, at the end of operation $\left(\mathrm{T}_{7}\right)$, on admission to the ICU $\left(\mathrm{T}_{\mathrm{ICU}}\right)$ and $2 \mathrm{~h}$ postoperatively ( $\mathrm{T}_{\text {ICU2h }}$ ). In both groups, a thoracic epidural catheter was inserted in the sitting position (Fig. 1a). After induction of GA, EDA was established by a bolus followed by a continuous rate of ropivacaine/ 


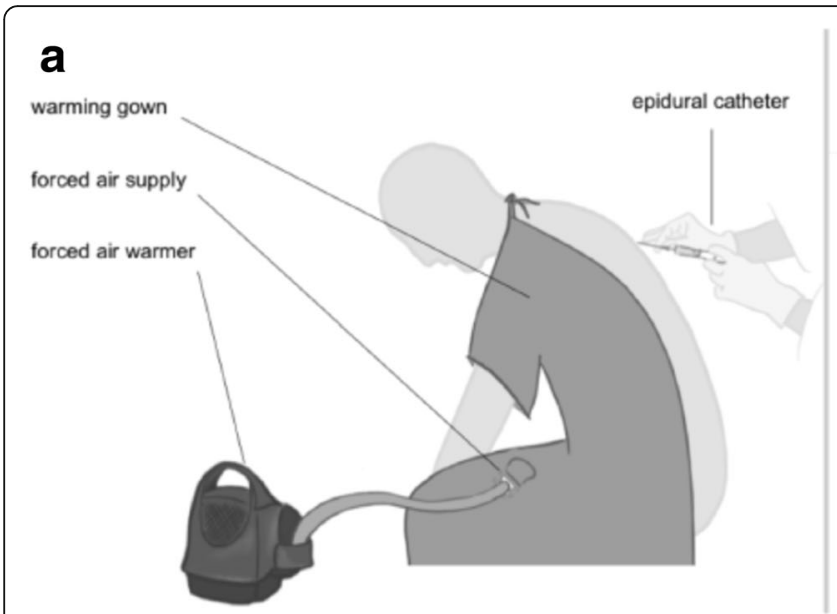

\section{b}

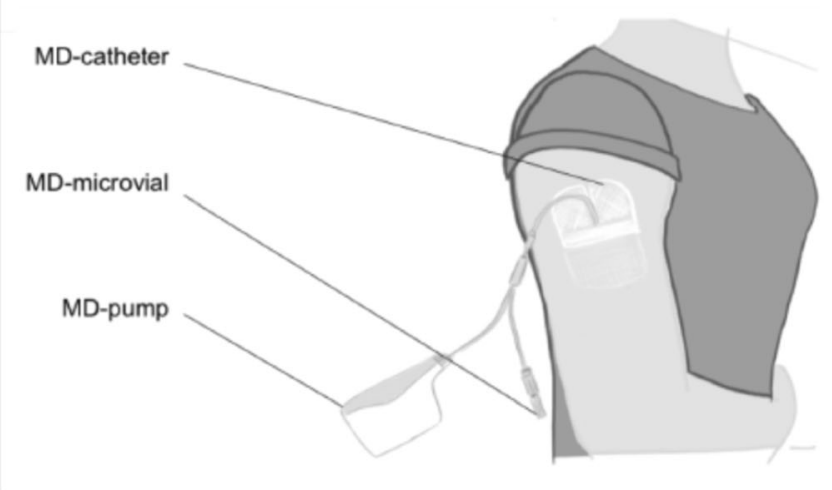

Fig. 1 a) Forced air prewarming during insertion of the epidural catheter; b) subcutaneous microdialyses in the upper arm

sufentanil (CADD ${ }^{\text {ts }}$ Solis pump, Smiths Medical, St. Paul, MN, USA). GA was induced using propofol, fentanyl and rocuronium for endotracheal intubation and maintained with sevoflurane with a minimum inspired oxygen concentration of $40 \%$ and an end-tidal $\mathrm{CO}_{2}$ concentration of 35 to $40 \mathrm{mmHg}$. Anaesthesia and muscle relaxation was maintained with repetitive bolusses of fentanyl and rocuronium. A central venous line (Arrow Medical Limited, Kington, UK) was placed into the internal jugular vein and blood pressure was measured by an arterial line (Vygon, Ecouen, France). During surgery, all intravenous (i.v.) fluids were infused using an active warming device (Level 1, Hot Line ${ }^{\mathrm{Tu}}$, Smiths Medicals, St. Paul, MN, USA). Women were warmed by forced air warming of the upper part of the body (Standard-group: $3 \mathrm{M}^{\mathrm{TN}}$ Bair Hugger ${ }^{\mathrm{Tm}}$ Intraoperative Blanket; PW-group: $3 \mathrm{M}^{\mathrm{sm}}$ Bair Paws ${ }^{\mathrm{Tm}}$ Flex Warming Gown) at $43^{\circ} \mathrm{C}$ until end of anesthesia. Forced air warming was shortly paused in both groups during disinfection of the belly before surgery. Postoperatively, women were transferred to the postanesthesia care unit (PACU). If patients showed clinical signs of hypovolemia (such as heart rate $(\mathrm{HR})>100 \mathrm{bpm}$, mean arterial pressure (MAP) $<60 \mathrm{mmHg}$, increased pulse pressure variation (PPV)) as well as hypovolemic changes in the hemodynamic monitoring (stroke volume variation (SVV), stroke volume (SV) and CO; Flo-Trac ${ }^{\mathrm{Tw}}$, Edwards Lifesciencess, Irvine, CA, USA) and in case of intraoperative volume- and blood loss, crystalloid infusion, gelatine infusion (500-1000 ml Gelafundin ${ }^{\mathrm{m}} 4 \%$ BBraun, Melsungen, Germany) and, if needed, fresh frozen plasma (FFP) and red blood cell concentrates (RBC) were given according to the transfusion- and hemodynamic algorithm of the standard operating procedures (SOP) of the Department of Anesthesiology and Intensive Care Medicine [20]. During surgery, $\mathrm{StO}_{2}$ was measured by near-infrared spectroscopy (InSpectra Spot Check, M300 ${ }^{\mathrm{mw}}$, Hutchinson,
MN, USA) on the thenar of the right hand. Central venous and arterial blood gas analysis to determine $\mathrm{dCO}_{2}$, lactate and hemoglobin $(\mathrm{Hb})$ were performed every $30 \mathrm{~min}$. Patients were extubated when spontaneous breathing was sufficient, body core temperature $>35.5 \mathrm{C}$ and no clinical symptoms of hypovolemia or hemodynamic instability. Postoperative pain relief was achieved using a patient-controlled epidural analgesia (PCEA) and women were transferred to PACU for at least $24 \mathrm{~h}$ after operation [20].

For MD, a $60 \mathrm{~mm}$ (inlet tubing diameter $1 \mathrm{~mm}$ ) flexible catheter (63 MD catheter, molecular weight cut-off of $2 \mathrm{kD}, \mathrm{M}$ Dialysis AB, Stockholm, Sweden) was placed into the subcutaneous fat tissue below the right deltoid muscle after local anesthesia (Fig. 1b). After perfusion with isotonic sterile fluid (perfusion fluid T1, M Dialysis AB) at a rate of $1 \mu \mathrm{l} / \mathrm{min}$ (MD Pump 106, M Dialysis AB) a dialysate was collected every $30 \mathrm{~min}$ (first sample at $\mathrm{T}_{3}$ ) in a $200 \mu \mathrm{l}$ microvial (M Dialysis $\mathrm{AB}$ ) and stored at $-20^{\circ} \mathrm{C}$ until analysis. At the end of surgery, the catheter was removed while the patient was still unconscious. All MD analysis were performed by the Experimental \& Clinical Research Center (ECRC) of the Franz-Volhard-Centrum, Charité-Universitätsmedizin Berlin, Campus Berlin-Buch.

The primary endpoint was defined as body core temperature drop $\left(\mathrm{BCT}_{\text {drop }}\right)$ from before epidural catheter placement $\left(\mathrm{T}_{1}\right)$ and after induction of GA $\left(\mathrm{T}_{2}\right)$ in the prewarming or standard group. Intra- and postoperative change of BCT up to $2 \mathrm{~h}$ after ICU admission, $\mathrm{StO}_{2}$ and hemodynamic parameters (PPV, SVV, SV), MAP, HR, norepinephrine usage, intraoperative transfusion rates (FFP, RBC), arterial lactate as well as the ethanol ratio, the glucose-, lactate- and glycerol concentration via MD were defined as secondary endpoints. In addition, the central venous-arterial $\mathrm{dCO}_{2}$, which depends on the $\mathrm{CO}_{2}$ production of the tissues and $\mathrm{CO}$, were measured as a marker for 
microperfusion [21]. Postoperatively, shivering and postoperative ventilation were obtained.

Sample size calculation was based on the assumption of a minimal difference of $0.5^{\circ} \mathrm{C}$ in body core temperature after prewarming compared to no prewarming (standard) [11]. A sample size of totally 48 patients, divided into two groups, was calculated to provide $80 \%$ power for detecting statistically significant difference at a two-tailed significance level of 0.05 (nQuery Advisor ${ }^{\mathrm{rm}}$, Release 7.0, Stat. Solutions Ltd. \& South Bank, Crosse's Green, Cork, Ireland). A dropout rate of $10 \%$ of patients not eligible for data sampling was included.

Data are reported as arithmetic mean [standard deviation (SD)] or median [25, 75\% percentile] (after rejection of normal distribution) or frequencies (\%). In order to assess differences in body core temperature as the primary outcome at timepoints $T_{1}-T_{7}$ the nonparametric (exact) Mann-Whitney-U test was used. Differences between the groups in terms of patient characteristics as well as secondary outcomes were compared with paired or unpaired t-test and chi-squared test. Frequencies were tested by the exact Mantel-Haenszel test (for ordered categories) or the exact Chi-square test (for unordered categories). A two-tailed $p$-value of $<0.05$ was considered statistically significant.

For MD subgroup analysis a sample size of 7 patients for each group was defined according to the study of Rosdahl et al. [10].

All calculations were performed with $\mathrm{R}$ software (version 3.3; R Foundation for Statistical Computing, Vienna, Austria).

The reporting of this RCT follows the updated guidelines for reporting parallel group randomized trials (CONSORT 2010 statement).

\section{Results}

During January 2015 and December 2017133 women were screened for eligibility. 85 patients did not meet the inclusion criteria (Fig. 2) and were excluded before randomization, leaving 48 women for randomization (Fig. 2). Data of 47 women were analyzed, as one woman had to be excluded due to termination of the procedure out of surgical reasons (Fig. 2).

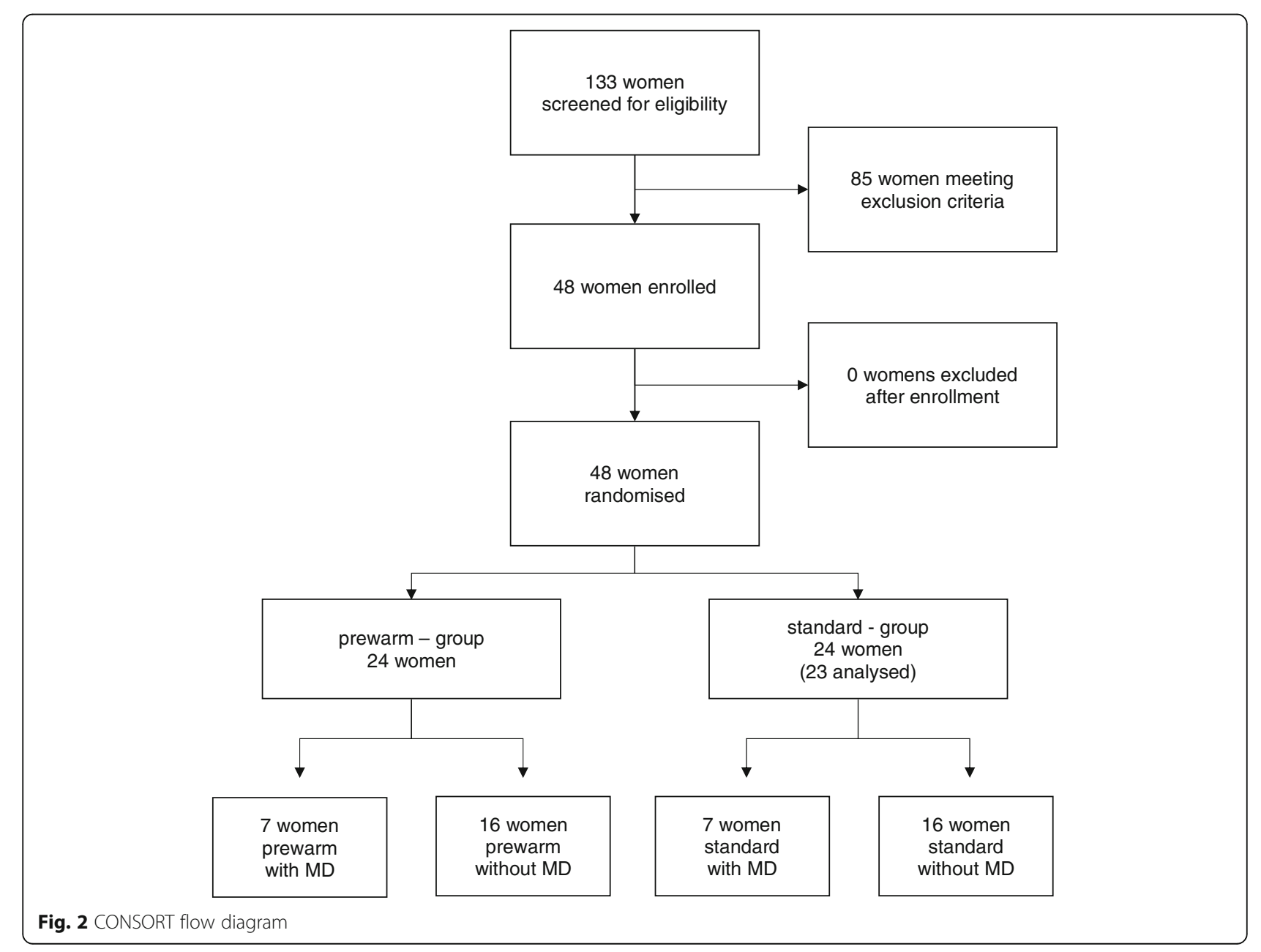


Besides a slight difference in height $(p=0.047)$, patient baseline characteristics, comorbidities and the duration of surgery did not differ significantly between the groups (Table 1). In multivariable linear regressions with group and BMI, group and age or group, BMI, and age as independent variables only group showed a significant relationship $(p<0.05)$ with body core temperature change.

Regarding the primary endpoint, the body core temperature change from $T_{1}$ (before) to $T_{2}$ amounted to $0.35{ }^{\circ} \mathrm{C}$ in the prewarm group and $0.9{ }^{\circ} \mathrm{C}$ in the standard group (Fig. 3) with a significant difference $(\Delta \mathrm{T})$ at $\mathrm{T}_{2}=0.55^{\circ} \mathrm{C}(p<0.005)$ between both groups (Fig. 3). No significant difference in baseline body core temperature $\left(T_{1}\right)$ was measured (Fig. 4). After a further decrease of the BCT between $\mathrm{T}_{2}$ and $\mathrm{T}_{3}$ with a significant $\Delta \mathrm{T}_{3}$ of $0.85^{\circ} \mathrm{C}(p<0,001)$ (Fig. 4) the $\mathrm{BCT}$ increased in both groups during the operation (Fig. 4). The core temperature remained higher in the prewarm

Table 1 Patient baseline characteristics, comorbidities and duration of surgery

\begin{tabular}{|c|c|c|c|c|}
\hline \multirow[b]{2}{*}{ Age (Years, mean \pm SD) } & \multicolumn{2}{|c|}{ prewarm $n=24$} & \multicolumn{2}{|c|}{ standard $n=23$} \\
\hline & 54,4 & $( \pm 11,7)$ & 61,3 & $(12,1)$ \\
\hline Weight (kg, mean \pm SD) & 73,6 & $(17,6)$ & 67,8 & $(10,3)$ \\
\hline Height (cm, mean $\pm S D)$ & 167 & $(4,9)$ & 164,0 & $(6,1)^{*}$ \\
\hline $\mathrm{BMI}($ mean $\pm \mathrm{SD})$ & 26,3 & $(5,8)$ & 25,4 & $(4,1)$ \\
\hline \multicolumn{5}{|l|}{ FIGO stage $(n, \%)$} \\
\hline । & 1 & (4) & 0 & $(0)$ \\
\hline$\|$ & 0 & (0) & 0 & $(0)$ \\
\hline III & 17 & (68) & 14 & $(64)$ \\
\hline IV & 5 & (20) & 4 & (18) \\
\hline \multicolumn{5}{|l|}{ Residual tumor after surgery ( $n, \%)$ : } \\
\hline $0 \mathrm{~cm}$ & 18 & $(72)$ & 17 & (77) \\
\hline $0-1 \mathrm{~cm}$ & 5 & (20) & 4 & (18) \\
\hline $1-2 \mathrm{~cm}$ & 1 & (4) & 1 & $(5)$ \\
\hline$>2 \mathrm{~cm}$ & 2 & (8) & 0 & $(0)$ \\
\hline Preoperative fasting (Liquids in hrs, mean \pm SD) & 11,3 & $(4,2)$ & 11,6 & $(3,8)$ \\
\hline Preoperative fasting (Solid in hrs, mean \pm SD) & 16,7 & $(4,7)$ & 16,2 & $(4,8)$ \\
\hline Coronary artery disease $(n, \%)$ & 0 & (0) & 1 & $(4,4)$ \\
\hline Heart failure $(n, \%)$ & 0 & (0) & 0 & $(0)$ \\
\hline Diabetes mellitus $(n, \%)$ & 1 & $(4,2)$ & 1 & $(4,4)$ \\
\hline Hypothyroidism $(n, \%)$ & 1 & $(4,2)$ & 4 & $(17.4)$ \\
\hline Renal failure $(n, \%)$ & 0 & (0) & 1 & $(4,4)$ \\
\hline Arterial hypertension $(n, \%)$ & 5 & $(20,8)$ & 7 & $(30,4)$ \\
\hline Peripheral arterial vascular disease $(n, \%)$ & 1 & $(4,2)$ & 1 & $(4,4)$ \\
\hline $\operatorname{COPD}(n, \%)$ & 1 & $(4,2)$ & 1 & $(4,4)$ \\
\hline Asthma $(n, \%)$ & 3 & $(12,5)$ & 2 & $(8,7)$ \\
\hline Thrombosis $(n, \%)$ & 3 & $(12,5)$ & 1 & $(4,4)$ \\
\hline Hyperthyroidism $(n, \%)$ & 1 & $(4,2)$ & 1 & $(4,4)$ \\
\hline Nicotine abuse $(n, \%)$ & 0 & (0) & 1 & $(4,4)$ \\
\hline Hyperlipoproteinemia $(n, \%)$ & 0 & (0) & 3 & $(13)$ \\
\hline \multicolumn{5}{|l|}{ ASA Classification $(n, \%)$ : } \\
\hline 1 & 4 & $(16,7)$ & 3 & (13) \\
\hline 2 & 12 & (50) & 14 & $(60,9)$ \\
\hline 3 & 8 & $(33,3)$ & 6 & $(26,1)$ \\
\hline Duration of surgery ${ }^{\S}(\min$, mean $\pm \mathrm{SD})$ & 334 & \pm 114 & 364 & \pm 134 \\
\hline
\end{tabular}

${ }^{*} p<0.05 ;{ }^{\varsigma}$ incision to suture; $S D$ Standard deviation, BMI body mass index, FIGO International Federation of Gynecology and Obstetrics, COPD chronic obstructive pulmonary disease, ASA American Society of Anesthesiologists 


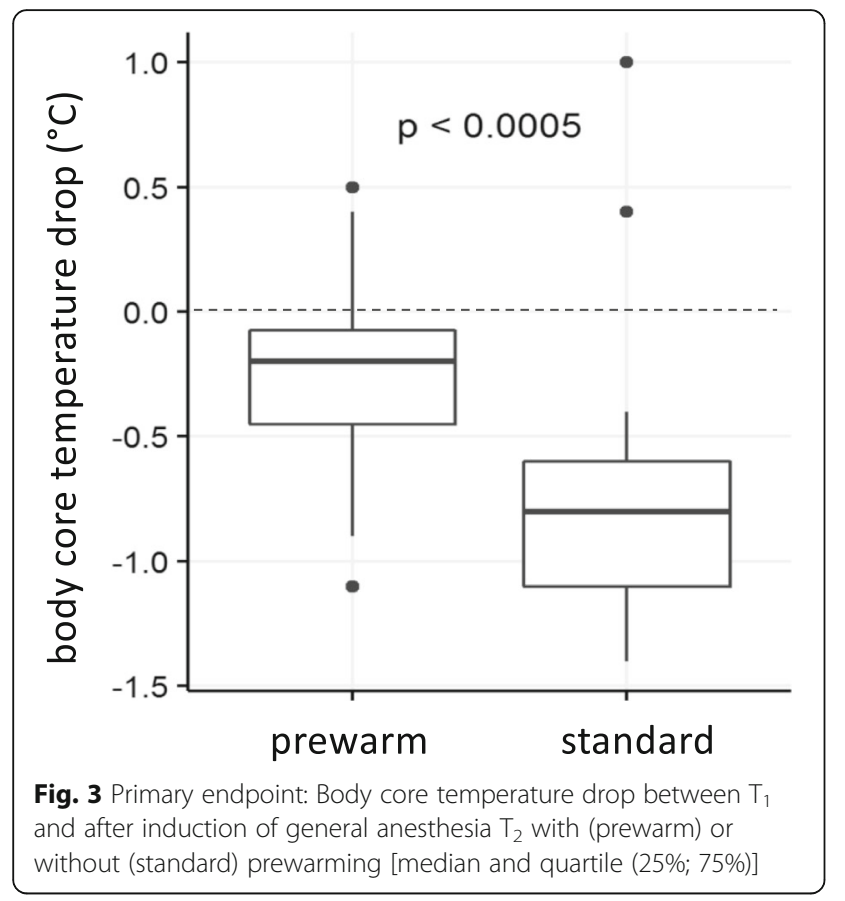

group over the entire observation period with a significant $\Delta \mathrm{T}$ at all time points from $\left(\Delta \mathrm{T}_{4}=0.9^{\circ} \mathrm{C}\right.$ up to $\Delta \mathrm{T}_{7}=0.95^{\circ} \mathrm{C}, p<0,001$, Fig. 4). At $\mathrm{T}_{\mathrm{ICU}}$ and at $\mathrm{T}_{\mathrm{ICU} 2 \mathrm{~h}}$ the body core temperatures in the PREWARM group were also higher than in the standard group (Fig. 5). One woman in the prewarm group suffered from hypothermia $\left(<36^{\circ} \mathrm{C}\right)$ temporarily while 17 women in the standard group were hypothermic at one time point and/or over the entire intraoperative observation period $(p<0,001)$. At $\mathrm{T}_{\mathrm{ICU}}$ six women in the standard group, but none in the prewarm group were subject to postoperative ventilation $(p<0.001)$ due to hypothermia at a median core temperature of $34.9^{\circ} \mathrm{C}(34.8 ; 35.0)$. Three women in the standard group at $\mathrm{T}_{\mathrm{ICU}}$ only, but none in the PREWARM group experienced postoperative shivering $(p>0.05)$.

$\mathrm{StO}_{2}$ increased from $86 \%\left(\mathrm{~T}_{3}\right)$ to $88 \%\left(\mathrm{~T}_{7}\right)$ in the prewarm group and was slightly, but not significantly, higher compared to $82 \%\left(\mathrm{~T}_{3}\right)$ and $85 \%\left(\mathrm{~T}_{7}\right)$ in the standard group. In both groups, the $\mathrm{dCO}_{2}$ did not change intraoperatively (median: prewarm $6.25 \mathrm{mmHg}$; standard $6.15 \mathrm{mmHg}$ ). Hemodynamic parameters such as SVV, SV and PPV as well as MAP, HR and norepinephrine concentration varied temporarily, depending on the volume changes in both groups, but without any significant differences between both groups at $\mathrm{T}_{3}, \mathrm{~T}_{4}$ and $\mathrm{T}_{5}$ (Table 2). FFP- and RBC transfusion were used in both groups with a non-significant difference between the groups (Table 2). The intraoperative arterial lactate concentration varied within the scope of $6 \mathrm{mg} / \mathrm{dl}\left(\mathrm{T}_{3}\right)$ to $7.5 \mathrm{mg} / \mathrm{dl}\left(\mathrm{T}_{7}\right)$ without significant differences between both groups.

For the ethanol ratio, the glucose-, lactate- and glycerol concentration [median (25. quartile/75. quartile)] measured by $M D$ from $T_{3}$ to $T_{7}$, no significant differences were detectable between the groups. On closer view, the ethanol ratio (Fig. 6) was temporarily reduced in the prewarm compared to the standard group, with comparable results at the end of surgery $\left(\mathrm{T}_{6}\right)$. The glucose concentration deferred from $2.05(0.36 / 0.36) \mathrm{mmol} / \mathrm{l}$ in the prewarm group versus $1.02(0.42 / 0.59) \mathrm{mmol} / \mathrm{l}$ in the standard group at $\mathrm{T}_{3}$ and proceeded almost similar in both groups between 1.51 $(0.44 / 0.87)$ and $2.1(1.35 / 0.35) \mathrm{mmol} / \mathrm{l}$ from $\mathrm{T}_{4}$ to $\mathrm{T}_{7}$. The glycerol concentration decreased continuously from 315 $(163 / 278) \mu \mathrm{mol} / \mathrm{l}$ at $\mathrm{T}_{3}$ to $191(21 / 185) \mu \mathrm{mol} / \mathrm{l}$ at $\mathrm{T}_{7}$ in the prewarm group and from $245(106 / 187) \mu \mathrm{mol} / \mathrm{l}$ at $\mathrm{T}_{3}$ to $119(52 / 131) \mu \mathrm{mol} / \mathrm{l}$ at $\mathrm{T}_{7}$ in the standard group. The lactate concentration of $0.66(0.17 / 0.07) \mathrm{mmol} / \mathrm{l}$ at $\mathrm{T} 3$ in the prewarm group was higher compared to $0.48(0.25 / 0.18)$ $\mathrm{mmol} / \mathrm{l}$ in the standard group and both concentrations aligned at $0.6(0.17 / 0.02) \mathrm{mmol} / \mathrm{l}$ at $\mathrm{T}_{6}$.

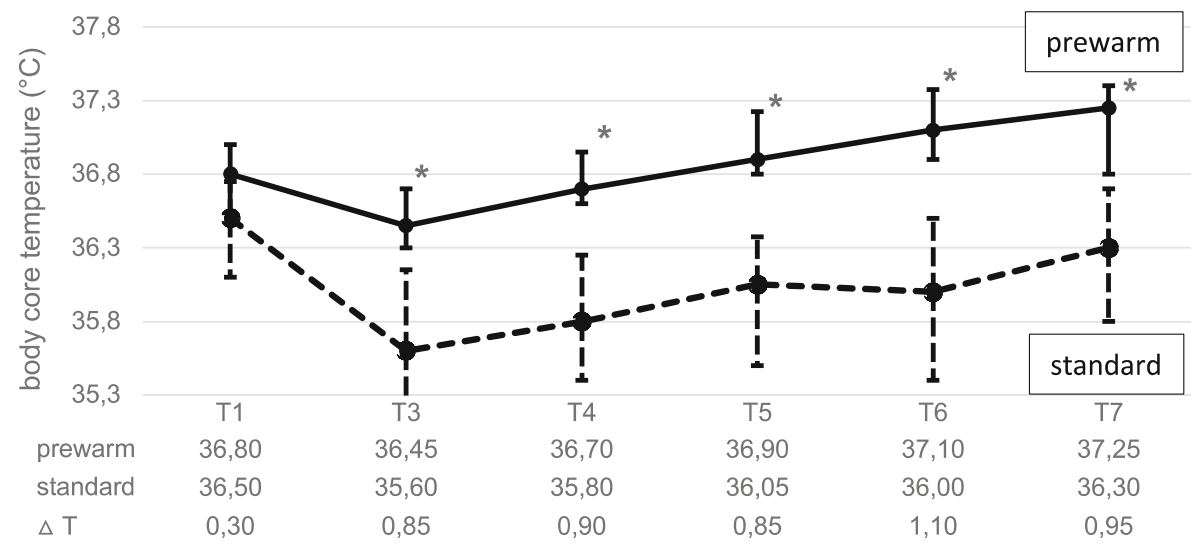

Fig. 4 Secondary endpoints: Body core temperature before prewarming $\left(T_{1}\right)$ and during operation $\left(T_{3}\right.$ to $\left.T_{6}\right)$ and at the end of surgery $\left(T_{7}\right)$ [median and quartile (25\%; 75\%); * $p<0,001]$ 


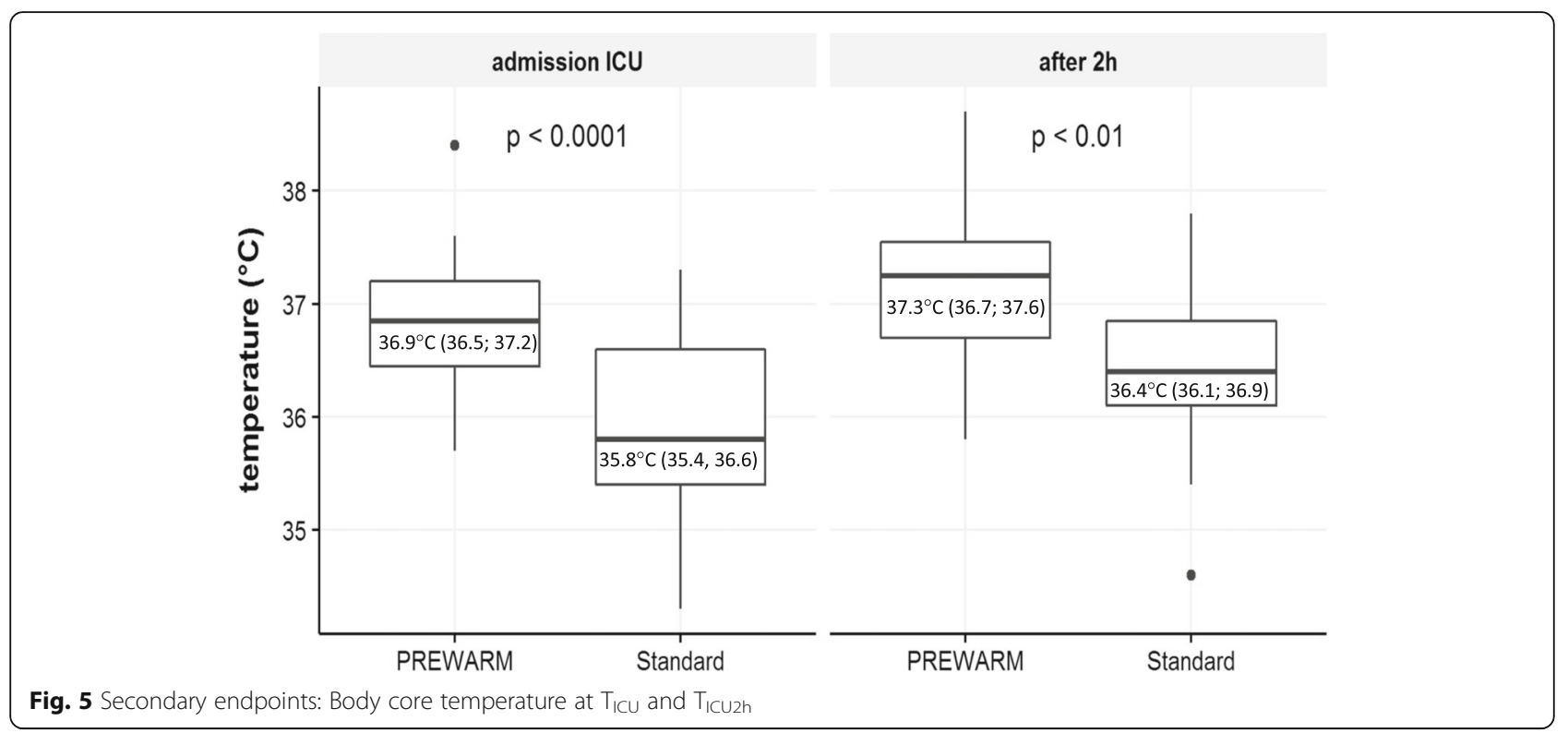

\section{Discussion}

In this study a forced-air prewarming interval at $43^{\circ} \mathrm{C}$ during epidural catheter placement and induction of GA showed efficacy to reduce core temperature drop and to maintain intraoperative normothermia during cytoreductive surgery not only throughout extended surgery but also at ICU admission and two hours thereafter. Furthermore, prewarming reduced the risk of postoperative ventilation due to hypothermia at the end of surgery. Microdialysis and $\mathrm{StO}_{2}$ showed better results for the prewarming group, however, this did not reach statistical significance. A reason for this may have been, that all hemodynamic parameters, transfusion rates, and $\mathrm{dCO}_{2}$ were not different in either study group. Nevertheless, small sample size for secondary outcomes should be taken into account for further discussions.

In a prospective randomized trial in 99 patients undergoing major abdominal surgery, Horn et al. [12] analyzed the effects of prewarming over $15 \mathrm{~min}$ before and after EDA versus $15 \mathrm{~min}$ after EDA or no prewarming. In contrast to our study, forced-air prewarming was performed at $44^{\circ} \mathrm{C}$ in a preoperative care unit before and after EDA, which requires higher logistical and staff demands than our approach [12]. Nevertheless, despite pre- and intraoperative forced-air warming the drop in body core temperature with induction of GA still occurs, which can be significantly alleviated by prewarming, which is in line with earlier results [12, 22].

At ICU admission only six women of the standard group but none in the prewarming group were mechanically ventilated on ICU because of hypothermia. These findings are in line with the findings of Horn et al. who measured a $34 \%$ postoperative ventilation rate in nonprewarmed patients, which indicates the importance of temperature management for ventilation times after surgery. Even $2 \mathrm{~h}$ after ICU admission prewarmed women of our study had a higher body core temperature without any shivering. Our data suggest, that the greater body core temperature drop after induction of GA in the standard seems to be irreversible in spite of all intraoperative approaches, such as intraoperative forced air warming, warm fluids etc., to warm up the patients during surgery effectively.

We hypothesized that $\mathrm{StO}_{2}, \mathrm{dCO}_{2}$, arterial lactate and parameters of MD may be useful as surrogate parameters to measure an improved microperfusion in prewarmed and normothermic patients. These markers did not differ significantly, but showed a trend in favor of the prewarm group, which may indicate the need for further studies powered to detect a difference in microcirculation parameters.

We measured a non-significant difference in $\mathrm{StO}_{2}$ in favor of the prewarmed patient group. It still remains unclear if this effect is caused by mild hypothermia-induced vasoconstriction and consecutive hypoperfusion and could be prevented by measures to maintain normothermia [23].

Our MD data could suggest that the tendency of a temporarily reduced ethanol ratio in prewarmed women after induction of GA and during the first hours of operations may represent an improved tissue perfusion [10]. After normothermia is reestablished due to intraoperative forced-air- warming and warmed transfusion/iv-fluids, the ethanol ratios showed similar values. This is consistent with the other microdialysis parameters. In 13 healthy volunteers, Rosdahl et al. demonstrated that the availability of glucose as a substrate for cell metabolism in subcutaneous fat tissue is dependent on tissue perfusion [10]. 
Table 2 Secondary endpoints: Intraoperative hemodynamic parameters at $T_{3-5}$ and total amount of transfusion at the end of surgery

\begin{tabular}{ccccc}
\hline & \multicolumn{2}{c}{ prewarm [mean; (SD)] } & \multicolumn{2}{c}{ standard [mean; (SD)] } \\
\hline MAP $(\mathrm{mmHg})$ & & & & \\
$\mathrm{T}_{3}$ & 80 & $( \pm 12)$ & 77 & $( \pm 18)$ \\
$\mathrm{T}_{4}$ & 77 & $( \pm 10)$ & 74 & $( \pm 17)$ \\
$\mathrm{T}_{5}$ & 78 & $( \pm 9)$ & 75 & $( \pm 17)$
\end{tabular}

HR (bpm)

$\begin{array}{lllll}\mathrm{T}_{3} & 62 & ( \pm 13) & 60 & ( \pm 15) \\ \mathrm{T}_{4} & 68 & ( \pm 12) & 65 & ( \pm 15) \\ \mathrm{T}_{5} & 72 & ( \pm 16) & 71 & ( \pm 19)\end{array}$

SW (\%)

$\begin{array}{lllll}\mathrm{T}_{3} & 9 & ( \pm 3) & 8 & ( \pm 3) \\ \mathrm{T}_{4} & 9 & ( \pm 3) & 9 & ( \pm 3) \\ \mathrm{T}_{5} & 9 & ( \pm 3) & 9 & ( \pm 3)\end{array}$

SV $(\mathrm{ml})$

$\begin{array}{lllll}\mathrm{T}_{3} & 69 & ( \pm 12) & 67 & ( \pm 16) \\ \mathrm{T}_{4} & 74 & ( \pm 18) & 73 & ( \pm 21) \\ \mathrm{T}_{5} & 81 & ( \pm 21) & 77 & ( \pm 24)\end{array}$

$\begin{array}{lllll}\mathrm{T}_{3} & 7 & ( \pm 3) & 7 & ( \pm 3) \\ \mathrm{T}_{4} & 9 & ( \pm 3) & 8 & ( \pm 3) \\ \mathrm{T}_{5} & 9 & ( \pm 5) & 9 & ( \pm 5)\end{array}$

Norepinephrine $(\mu \mathrm{g} / \mathrm{kg} / \mathrm{min})$

$\begin{array}{lllll}\mathrm{T}_{3} & 0.03 & ( \pm 0.02) & 0.03 & ( \pm 0.02) \\ \mathrm{T}_{4} & 0.06 & ( \pm 0.04) & 0.06 & ( \pm 0.04) \\ \mathrm{T}_{5} & 0.07 & ( \pm 0.05) & 0.07 & ( \pm 0.04) \\ \text { ransfusion }(\mathrm{ml}) & & & & \\ \text { FFP at } \mathrm{T}_{7} & 3500 & ( \pm 2300) & 3700 & ( \pm 2200) \\ \text { RBC at } \mathrm{T}_{7} & 1000 & ( \pm 600) & 1000 & ( \pm 900)\end{array}$

${ }^{*} p<0.05 ;$ MAP mean arterial pressure, HR heart rate, SVV Stroke volume variation, SV Stroke volume, PPV pulse pressure variation, FFP fresh frozen plasma, $R B C$ red blood cells concentrates
Therefore, the glucose recovery rate in MD acts approximately inverse to the ethanol ratio [10]. This might explain the increased glucose concentration in the prewarmed group at the beginning of surgery when perfusion may be improved due to the higher body core temperature compared to the standard group. Moreover, an increase of the lactate concentration in MD represents hypoperfusion and oxygen deficit in the subcutaneous tissue, as Bahlmann et al. demonstrated after 15-60 min of aortic clamping [24]. Potential hypoperfusion of the subcutaneous tissue due to reduced body core temperature did not result in an increase of the lactate concentration in the standard group with MD. On the other hand, the glycerol concentration in MD represents increased metabolic stress and lipolytic activity in the standard group [24]. Unfortunately and similar to lactate, the concentration remained without significant changes and differences between the groups. It may be hypothesized that mild hypothermia or reduced body core temperature are not very likely to result in a detectable increase of lactate and glycerol in MD. Nevertheless, the MD parameters give a first impression of temperature-related effects on microperfusion and that MD may be a promising technique to identify surrogate parameters for the impact of hypothermia. So far, no comparable data of $\mathrm{MD}$ in dependence of changes in body core temperature are published.

\section{Limitations}

Our study has a few limitations: Firstly, the study was powered in regards to primary outcome. In terms of secondary outcome, the study was not powered to detect significant changes, but may allow for an estimation of the number of patients needed for upcoming investigations on microperfusion and MD. Secondly, $\mathrm{StO}_{2}$ was evaluated without reference values of an accompanied vascular occlusion test on the upper arm due to potential disruption

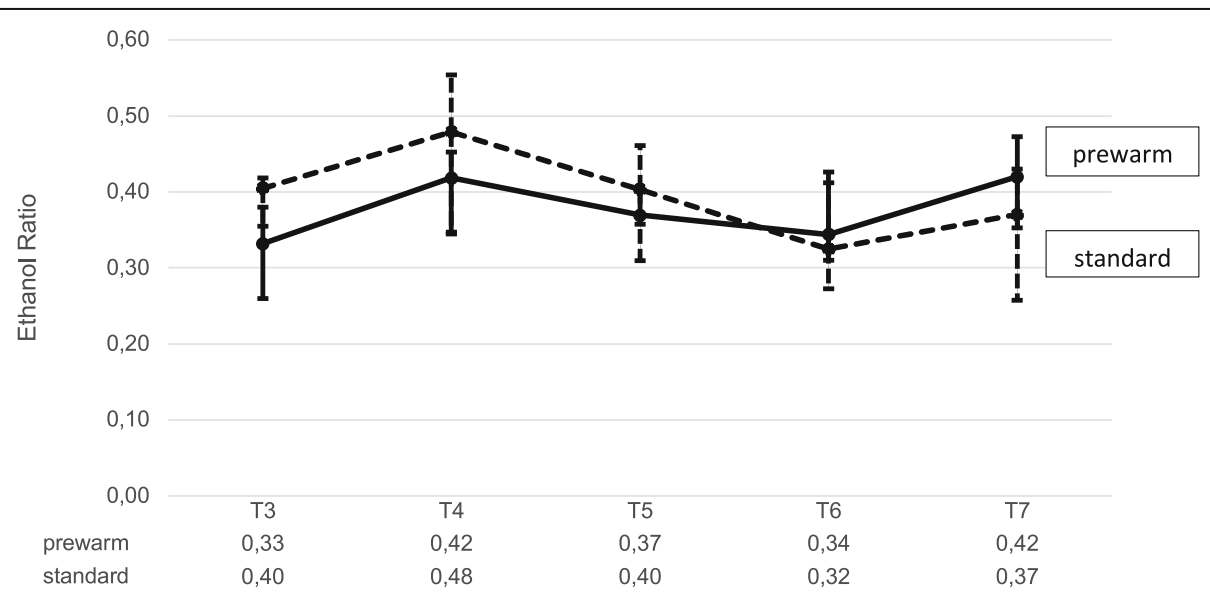

Fig. 6 Secondary endpoints: Ethanol ratio in MD before prewarming $\left(T_{1}\right)$ and during operation $\left(T_{4}\right.$ to $\left.T_{6}\right)$ and at the end of surgery $\left(T_{7}\right)[$ median and quartile $(25 \% ; 75 \%)]$ 
and damage to the microdialysis catheter, which was inserted on the same side. Lastly, prewarming did not allow a blinding at all times. A concealed randomization was performed. Furthermore the anesthesiologist in charge of the patient was not involved in the collection of study related data. So the likelihood of bias was reduced.

\section{Conclusion}

In conclusion, forced-air prewarming at $43{ }^{\circ} \mathrm{C}$ during epidural catheter placement and induction of GA without interfering with the perioperative routine setting is effective to reduce the core temperature drop. Furthermore, prewarming maintains intraoperative normothermia until the end of surgery and up to two hours after ICU admission without any shivering or mechanically ventilation due to hypothermia postoperatively. A statistically significant impact of prewarming on microperfusion as measured by MD could not be detected by this study. However, reduced ethanol ratio and increased glucose concentration in the microdialysis as well as an increased tissue oxygenation may point to a better maintained microperfusion in prewarmed patients compared to those receiving standard treatment. The use of hemodynamic parameters, transfusion rates, $\mathrm{StO}_{2}, \mathrm{dCO}_{2}$ and $\mathrm{MD}$ parameters as surrogate parameters influencing microperfusion should be controlled in further randomized, controlled studies investigating the impact of temperature management in surgical patients.

\section{Abbreviations \\ $\mathrm{BCT}$ : body core temperature; $\mathrm{BCT}_{\text {drop: }}$ drop in body core temperature; CO: cardiac output; CRF: case reporting form; $\mathrm{dCO}_{2}$ : carbon dioxide difference; ECRC: Experimental \& Clinical Research Center; EDA: Epidural anesthesia; FFP: fresh frozen plasma; GA: General anesthesia; GFR: glomerular filtration rate; GINA: Global Initiative for Asthma; HR: heart rate; i.v.: intravenous; ICU: Intensive Care Unit; LV-EF: left ventricular ejection fraction; MAP: mean arterial pressure; MD: microdialysis; OR: operating room; PACU: post-anesthesia care unit; PCEA: patient-controlled epidural analgesia; PPV: pulse pressure variation; PW: prewarming; RBC: red blood cell concentrates; SD: standard deviation; SOP: standard operating procedures; $\mathrm{StO}_{2}$ : tissue oxygenation; $\mathrm{SV}$ : stroke volumen; $\mathrm{SW}$ : stroke volume variation; $\mathrm{T}_{1}$ : Temperature at time before induction of anesthesia; $\mathrm{T}_{2}$ : Temperature after induction of anesthesia; $T_{3}$ : Temperature after $15 \mathrm{~min}$ of induction of anesthesia; $\mathrm{T}_{4}$ : Temperature after $60 \mathrm{~min}$ of induction of anesthesia; $T_{5}$ : Temperature after $120 \mathrm{~min}$ of induction of anesthesia; $T_{6}$ : Temperature after $180 \mathrm{~min}$ of induction of anesthesia; $\mathrm{T}_{7}$ : Temperature at the end of operation; $T_{\text {ICU: }}$ Temperature on admission to the ICU; TICU2h: Temperature until $2 \mathrm{~h}$ after ICU admission}

\section{Acknowledgements}

Not applicable

\section{Study presentation}

This trial was presented in parts at the annual meetings of the American Society of Anesthesiologists 2017 and the European Society of Anesthesiology 2018.

\section{Authors contribution}

Substantial contributions to conception and design: LK, CVH, PN. Acquisition of data: PN, TB, SC, MB. Analysis and Interpretation of data: AB, JS, MB, CS, $A H, C v H$. Drafting the manuscript: $L K, A B$. Revision of the manuscript: PN, TB,
SC, JS, MB, CS, AH, CvH. Final approval: LK, PN, TB, SC, JS, AB, MB, CS, AH, $\mathrm{CvH}$. Agreement to be accountable for all aspects of the work: LK, PN, TB, SC, $J S, A B, M B, C S, A H, C v H$. All Authors meet the criteria for authorship according to the ICMJE guidelines.

\section{Funding}

This investigator initiated trial was funded by $3 \mathrm{M}$ Deutschland $\mathrm{GmbH}$ without any involvement of the funding body on study design, data collection, analysis, interpretation of data and in writing the manuscript. The corresponding author had full access to all study data.

\section{Availability of data and materials}

The datasets used and analyzed during the current study are available from the corresponding author on reasonable request. The complete trial protocol for this investigator-initiated trial is available in German only and can be requested by the corresponding author.

\section{Ethics approval and consent to participate}

This trial was performed in accordance with the Declaration of Helsinki and was approved by the local ethics board (Ethics Committee of CharitéUniversitätsmedizin Berlin) - registration number: EA1/348/14.

All patients gave written informed consent, prior to entering the study.

\section{Consent for publication}

Not applicable

\section{Competing interests}

$\mathrm{PN}, \mathrm{TB}, \mathrm{SC}, \mathrm{AB}, \mathrm{JS}, \mathrm{MB}, \mathrm{AH}$ have no conflict of interest. LK reports grants from $3 \mathrm{M}$ during the conduct of the study; personal fees from HICC Deutschland GbR., Novo Nordisk, Sintetica, CSL Behring, outside the submitted work. CvH reports personal fees from Bayer AG, CSL Behring, Boehringer Ingelheim, Pfizer GmbH, Bristol Myers Squibb, Shire, Ferring GmbH, Sanofi Aventis, Mitsubishi Pharma, Novo Nordisk, HICC GbR, grants and personal fees from Daiichi Sankyo, outside the submitted work.

CS received funding from European Union funded seventh framework research program (FP7/2007-2013), under the grant agreement No. HEALTH-F2-201460246, Bio Cog, grants from Dr. Köhler Chemie GmbH, AppAdventure, J\&P Medical Research Ltd., Pharmaceutical Research Associate GmbH, Delcath Systems Inc., INC Research UK Ltd., La Jolla Pharmaceutical Company, ARIDIS Pharmaceutical Inc., B. Braun Melsungen AG, Drägerwerk AG \& CoKGaA, Grünenthal GmbH, Infectopharm GmbH, Sedana Medical Ltd., Arbeitsgemeinschaft industrieller Forschungsvereinigungen "Otto von Guericke" e.V. (AiF)/German Federation of Industrial Research Associations, Berufsverband deutscher Anästhesisten e.V. (BDA)/ Professional Associationof German Anaesthesiologists, Deutsche Forschungsgemeinschaft/ German Research Society, Deutsches Zentrum für Luft- und Raumfahrttechnik e.V. (DLR)/German Aerospace Center, Einstein Stiftung Berlin/Einstein Foundation Berlin, European Society of Anaesthesiology, Gemeinsamer Bundesausschuss/Federal Joint Commitee (G-BA), inneruniversitäre Forschungsförderung/Inner university grant, Projektträger im DLR/Project Management Agency, Stifterverband/Non-Profit Society Promoting Science and Education, WHOCC, Westfälische Wilhelms- Universität Münster/ DFG, AbbVie Deutschland GmbH \& CoKG, Aguettant Deutschland GmbH, MAQUET Vertrieb und Service Deutschland $\mathrm{GmbH}$, Orion Pharma GmbH, Philips Electronics Nederland B.V., Sintetica GmbH, Baxter Deutschland GmbH, Biotest AG, Cytosorbents Europe GmbH, Edwards Lifesciences Germany GmbH, Fresenius Medical Care, Masimo Europe Ltd., Medtronic GmbH, Pfizer Pharma PFE GmbH, European Commission, BMUB (Bundesministerium für Umwelt, Naturschutz und nukleare Sicherheit), personal fees from B. Braun Melsungen AG, Georg Thieme Verlag; outside the submitted work. CS has a patent 102014 215211.9 pending, a patent application No. PCT/EP2015/067730 pending to Graft Gesellschaft von Architekten mbH and a patent application No. PCT/ EP2015/067731 pending to Graft Gesellschaft von Architekten mbH. All authors report no conflict of interest relating to this work.

\section{Author details}

'Department of Anaesthesiology and Operative Intensive Care Medicine (CCM, CVK), Charité-Universitätsmedizin Berlin, Corporate Member of Freie Universität Berlin, Humboldt-Universität zu Berlin, and Berlin Institute of Health, Campus Virchow-Klinikum, Augustenburger Platz 1, 13353 Berlin, Germany. ${ }^{2}$ Department of Anaesthesia, Intensive Care Medicine, Emergency Medicine and Pain Therapy, Vivantes Klinikum im Friedrichshain, Berlin, 
Germany. ${ }^{3}$ Department of Gynaecology, Charité-Universitätsmedizin Berlin, Berlin, Germany. ${ }^{4}$ Institut für Klinische Chemie und Pathobiochemie, Klinikum rechts der Isar der Technischen Universität München, Munich, Germany. ${ }^{5}$ Experimental \& Clinical Research Center, ECRC, Charité-Universitätsmedizin Berlin CCB, Berlin, Germany.

Received: 20 February 2019 Accepted: 7 August 2019

Published online: 22 August 2019

\section{References}

1. Forstot RM. The etiology and management of inadvertent perioperative hypothermia. J Clin Anesth. 1995;7(8):657-74.

2. Grote R, Wetz AJ, Bräuer A, Menzel M. Prewarming according to the AWMF S3 guidelines on preventinginadvertentt perioperative hypothermia 2014:: retrospective analysis of 7786 patients. Anaesthesist. 2018;67(1):27-33.

3. Sessler DI. Perioperative thermoregulation and heat balance. Lancet. 2016;387(10038):2655-64.

4. Sessler DI. Perianesthetic thermoregulation and heat balance in humans. FASEB J. 1993;7(8):638-44.

5. Fotopoulou C, Savvatis K, Steinhagen-Thiessen E, Bahra M, Lichtenegger W, Shouli J. Primary radical surgery in elderly patients with epithelial ovarian Cancer. Int J Gynecol Cancer. 2010;20:34-40.

6. Kurz A, Go JC, Sessler DI, Kaer K, Larson MD, Bjorksten AR. Alfentanil slightly increases the sweating threshold and markedly reduces the vasoconstriction and shivering thresholds. Anesthesiology. 1995;83(2):293-9.

7. Michelson AD, MacGregor H, Barnard MR, Kestin AS, Rohrer MJ, Valeri CR. Reversible inhibition of human platelet activation by hypothermia in vivo and in vitro. Thromb Haemost. 1994;71(5):633-40.

8. Schmied H, Reiter A, Kurz A, Sessler DI, Kozek S. Mild hypothermia increases blood loss and transfusion requirements during total hip arthroplasty. Lancet. 1996;347(8997):289-92.

9. Kurz A, Sessler DI, Lenhardt R. Perioperative normothermia to reduce the incidence of surgical-wound infection and shorten hospitalization. Study of wound infection and temperature group. N Engl J Med. 1996;334(19):1209-15.

10. Rosdahl H, Ungerstedt U, Jorfeldt L, Henriksson J. Interstitial glucose and lactate balance in human skeletal muscle and adipose tissue studied by microdialysis. J Physiol. 1993:471(1):637-57.

11. Horn E-P, Bein B, Böhm R, Steinfath M, Sahili N, Höcker J. The effect of short time periods of pre-operative warming in the prevention of perioperative hypothermia: pre-operative warming in the prevention of perioperative hypothermia. Anesthesia. 2012;67(6):612-7.

12. Horn EP, Bein B, Broch O, Iden T, Böhm R, Latz S-K, et al. Warming before and after epidural block before general anesthesia for major abdominal surgery prevents perioperative hypothermia: A randomized controlled trial. Eur J Anaesthesiol. 2016;33(5):334-40.

13. Vanni SMD, Braz JRC, Módolo NSP, Amorim RB, Rodrigues GR. Preoperative combined with intraoperative skin-surface warming avoids hypothermia caused by general anesthesia and surgery. J Clin Anesth. 2003;15(2):119-25.

14. Andrzejowski J, Hoyle J, Eapen G, Turnbull D. Effect of prewarming on postinduction core temperature and the incidence of inadvertent perioperative hypothermia in patients undergoing general anesthesia. $\mathrm{Br} J$ Anaesth. 2008;101(5):627-31.

15. Wong PF, Kumar S, Bohra A, Whetter D, Leaper DJ. Randomized clinical trial of perioperative systemic warming in major elective abdominal surgery. Br J Surg. 2007;94(4):421-6

16. Torossian A, Bein B, Bräuer A. German S3 Guideline „Vermeidung von perioperativer Hypothermie". AWMF Register. 2014;001-018.

17. Camus Y, Delva E, Sessler DI, Lienhart A. Pre-induction skin-surface warming minimizes intraoperative core hypothermia. J Clin Anesth. 1995;7(5):384-8.

18. Melling AC, Ali B, Scott EM, Leaper DJ. Effects of preoperative warming on the incidence of wound infection after clean surgery: a randomized controlled trial. Lancet. 2001;358(9285):876-80.

19. Mäkinen MT, Pesonen A, Jousela I, Päivärinta J, Poikajävi S, Albäck A, et al. Novel zero-heat-flux deep body temperature measurement in lower extremity vascular and cardiac surgery. J Cardiothorac Vasc Anesth. 2016;30: 973-8.

20. Spies C, Kerner T, Kastrup M, Melzer-Gartzke C, Zielke H. SOPs in Anästhesiologie und Schmerztherapie. Stuttgart: Thieme Verlag 2013. ISBN: 9783131694317.

21. Futier $\mathrm{E}$, Robin $\mathrm{E}$, Jabaudon $\mathrm{M}$, Guerin $\mathrm{R}$, Petit $\mathrm{A}$, Bazin J-E, Constantin J-M, Vallet $\mathrm{B}$. Central venous $\mathrm{O} 2$ saturation and venous-to-arterial $\mathrm{CO} 2$ difference as complementary tools for goal-directed therapy during high-risk surgery. Crit Care. 2010;14(5):R193.

22. Lau A, Lowlaavar N, Cooke EM, West N, German A, Morse DJ, et al. Effect of preoperative warming on intraoperative hypothermia: a randomized controlled trial. Can J Anesth/J Can Anesth. 2018;65:1029.

23. Cho YJ, Lee SY, Kim TK, Hong DM, Jeon Y. Effect of Prewarming during induction of anesthesia on microvascular reactivity in patients undergoing off-pump coronary artery bypass surgery: a randomized clinical trial. PLoS One. 2016;11(7):e0159772.

24. Bahlmann L, Wagner $K$, Heringlake $M$, Wirtz C, Fütterer T, Schmucker $P$, et al. Subcutaneous microdialysis for metabolic monitoring in abdominal aortic surgery. J Clin Monit Comput. 2002;17(5):309-12.

\section{Publisher's Note}

Springer Nature remains neutral with regard to jurisdictional claims in published maps and institutional affiliations.
Ready to submit your research? Choose BMC and benefit from:

- fast, convenient online submission

- thorough peer review by experienced researchers in your field

- rapid publication on acceptance

- support for research data, including large and complex data types

- gold Open Access which fosters wider collaboration and increased citations

- maximum visibility for your research: over $100 \mathrm{M}$ website views per year

At BMC, research is always in progress.

Learn more biomedcentral.com/submissions 